\title{
Conhecer e educar para controlar o câncer na Bahia ${ }^{1}$
}

\section{Knowing and educating to control cancer in Bahia}

\author{
Christiane Maria Cruz de Souza²
}

\begin{abstract}
RESUMO
Um dos pontos que serão desenvolvidos neste artigo é o processo educativo iniciado por médicos para conferir visibilidade ao câncer e mobilizar a sociedade em torno da doença na Bahia, Brasil, entre as décadas de 1840 e 1950. Dentro dos limites permitidos por este texto, pretende-se analisar as transformações ocorridas nas teorias e tecnologias biomédicas que interferiram no esforço de cognição e de resposta à doença, assim como as consequências destas definições na estruturação dos cuidados médicos.

Palavras-chave: câncer; educação; saúde; medicina; doença.
\end{abstract}

\begin{abstract}
One of the points that will be developed in this article is the educational process initiated by physicians to give visibility to cancer and mobilize society around the disease in Bahia, Brazil, between the 1840s and 1950s. Within the limits allowed by this text, there is the intention to analyze the changes which have occurred in the theories and biomedical technologies that interfered in the effort of cognition and response to that disease, as well as the consequences of these definitions in the structuring of health care.
\end{abstract}

Keywords: cancer; education; health; medicine; disease.

DOI: $10.1590 / 0104-4060.38203$

1 As reflexões aqui apresentadas resultaram do projeto de pesquisa Saúde, gênero e assistência na Bahia (séculos XIX e XX) financiado e desenvolvido no Instituto Federal de Educação, Ciência e Tecnologia da Bahia (IFBA). Relaciona-se, igualmente, com os estudos realizados no âmbito do Núcleo de Tecnologia em Saúde da IFBA.

2 Instituto Federal de Educação, Ciência e Tecnologia da Bahia. Núcleo de Tecnologia em Saúde. Salvador, Bahia, Brasil. Rua Emídio dos Santos, s/n. CEP: 40300-010. 
In some ways disease does not exist until we have agreed that it does, by perceiving, naming, and responding to it.

Charles E. Rosenberg

\section{Introdução}

Para Charles Rosenberg (1992, p. 307), não há nenhuma doença até que nós concordemos que ela exista, percebendo-a, nomeando-a, apresentando-lhe algum tipo de resposta. $\mathrm{O}$ autor afirma que, embora a doença seja um evento biológico, constitui-se, igualmente, em evento social na medida em que incide em um contexto humano. Seguindo Rosenberg, assumimos que a doença é um evento biossocial, que envolve negociação e consenso e como tal, em sua percepção e definição interferem variáveis como teorias médico-científicas, valores culturais e interesses de diferentes atores sociais. Assim, o esforço de cognição de uma doença sofre influência do contexto em que esta insurge, mas pode também provocar respostas políticas, científicas, tecnológicas, econômicas e socioculturais que interferiram em tal contexto ${ }^{3}$.

Doença silenciosa, pouco conhecida, o câncer foi por longo período de tempo ignorado pelas autoridades públicas e pela sociedade baiana e brasileira em geral. Além de consumir muito tempo, o processo de cognição e resposta ao câncer no Brasil e, em especial, na Bahia, demandou grande esforço e dependeu da ação conjunta de diversas personagens, instâncias e instituições. Enquanto na Europa as instituições voltadas para o atendimento de doentes com câncer datavam de meados do século XIX, a criação da Liga Bahiana Contra o Câncer (LBCC) data de 1936 e o projeto de construção do Instituto de Câncer da Bahia, atual Hospital Aristides Maltez (HAM), levou décadas para se concretizar.

Um dos pontos que se pretende discutir neste artigo é o processo educativo de iniciativa da classe médica para conferir visibilidade ao câncer e mobilizar a sociedade em torno da doença na Bahia, Brasil. Dentro dos limites permitidos por este texto, pretende-se analisar as transformações ocorridas nas teorias e tecnologias biomédicas que interferiram no esforço de cognição e de resposta à doença, e as consequências destas definições na estruturação dos cuidados médicos. As balizas cronológicas estabelecidas para este trabalho têm como limites a década de 1840, período em que são publicadas as primeiras teses sobre

3 Charles Rosenberg (1992, p. 307) utiliza o termo metafórico frame para descrever a confecção de esquemas explicativos para determinadas doenças. 
o assunto na Faculdade de Medicina da Bahia, e a década de 1950, período em que é inaugurado e começa a funcionar em Salvador o Hospital Aristides Maltez, hospital filantrópico especializado no tratamento da doença.

Para a realização deste texto, foram utilizadas fontes primárias diversas, dentre essas, os jornais de circulação diária em Salvador. A imprensa baiana veiculou uma série de matérias informativas sobre as características, sintomas, sinais e manifestações da doença; divulgou métodos preventivos e terapêuticos; noticiou avanços da tecnologia biomédica aplicada ao diagnóstico e à terapêutica da enfermidade; deu visibilidade às políticas públicas e ações filantrópicas relacionadas ao controle do câncer; veiculou notas sobre a realização de palestras e cursos de qualificação voltados para os profissionais da saúde.

Além dos jornais em circulação em Salvador, foram examinados os boletins editados pela Liga Bahiana Contra o Câncer e pelo Hospital Aristides Maltez: o $H A M$ - Boletim do Hospital Aristides Maltez; O Câncer-Boletim de Divulgação da Liga Bahiana Contra o Câncer; e os Arquivos de Oncologia da Liga Bahiana Contra o Câncer. Esses boletins veiculavam a história da LBCC, do HAM e os relatórios das gestões; divulgavam as campanhas para o controle da doença, como também as promovidas pela LBCC para arrecadar recursos financeiros para a construção e manutenção do HAM; traziam informações diversas sobre a doença, alertando sobre a necessidade do diagnóstico precoce e as novas tecnologias disponíveis para o controle da doença, dentre outras informações.

A Gazeta Médica da Bahia, periódico criado em 1866, pelos médicos que compunham o núcleo inicial da Escola Tropicalista Baiana - Wucherer, Paterson e Silva Lima - também foi fonte importante de informações para este trabalho. A Gazeta representou e representa importante instrumento de divulgação do conhecimento e tecnologias biomédicas produzido nos centros de pesquisa do Brasil e do mundo.

Assim como os artigos publicados na Gazeta Médica da Bahia e os boletins do HAM ou da LBCC, as teses publicadas pela Faculdade de Medicina da Bahia trazem pistas importantes sobre o conhecimento em circulação nos meios científicos e acadêmicos da Bahia, do Brasil e até do mundo. Tais publicações contribuíram para ampliar a nossa compreensão do processo de definição da doença e do aporte científico utilizado para explicá-la. Ao mesmo tempo, essas fontes nos forneceram informações importantes sobre o conhecimento, a tecnologia e a prática médica.

Este texto se dividirá em duas partes. O processo de cognição do câncer no âmbito do espaço científico e acadêmico será o primeiro ponto a ser apresentado. Em seguida serão discutidos os meios utilizados pelos médicos, especialmente, e pela Liga Bahiana Contra o Câncer para qualificar os profissionais da saúde e divulgar informações sobre a doença ao público. 


\section{O processo de cognição do câncer}

As teses doutorais de final de curso e as apresentadas nos concursos de acesso ao corpo docente da Faculdade de Medicina da Bahia comprovam que o câncer era objeto da atenção dos médicos baianos desde a década de 1840 (MEIRELES et al., 2004, p. 9-101). Em 1843, por ocasião de um concurso para professor substituto da seção de cirurgia da Faculdade de Medicina da Bahia, Antônio José Ozório apresentou uma tese sobre o câncer de útero. Em seu trabalho, o médico fez um mapeamento dos estudos sobre a doença, realizados nos principais centros de pesquisa da época. Ozório apoiou-se, sobretudo, na obra publicada pelo médico francês Pierre-Jérôme-Sébast Téallier, em 1836, intitulada Traité Du Cancer de La Matrice, de ses causes, de son diagnostic et de son traitement ${ }^{4}$.

Apesar de não se tratar de conhecimento original, fruto de pesquisa realizada pelo próprio médico, a tese de Antônio Ozório revela que, apesar da juventude da Faculdade de Medicina da Bahia, se comparada às congêneres do continente europeu ou mesmo das Américas, por ali circulava o conhecimento produzido nos grandes centros de pesquisa do mundo. Nota-se, também, forte influência da medicina francesa no ensino praticado por esta Instituição até as reformas acadêmico-administrativas ocorridas entre 1879 e $1884^{5}$.

Assiste-se, naquela altura, ao que Foucault denominou de "nascimento da clínica" cujos princípios básicos serão dominantes na medicina baiana por longo tempo. Os adeptos da clínica cuidavam de registrar sintomas e sinais após submeter o doente a um interrogatório minucioso e a uma pesquisa clínica sistemática e rigorosa. A investigação anatomopatológica também se constituía em prática comum entre os médicos baianos, que examinavam os tecidos e órgãos internos para identificar lesões e confirmar o diagnóstico.

O trabalho que serviu de base para Antônio Ozório construir a sua tese era resultado de investigação clínica desenvolvida por Pierre-Jérôme-Sébast Téallier, que era Membro Residente da Sociedade de Medicina de Paris. Seguindo Téallier, Antônio Ozório descreve os sintomas e sinais que identificavam a doença, percebidos através do exame clínico: a cor, a consistência, o formato da lesão e o odor característico, como também o relato de dores, a palidez, a rápida perda de peso e astenia da paciente.

4 Em tradução livre: Tratamento do câncer do útero, de suas causas, de seu diagnóstico e de seu tratamento.

5 Para saber mais sobre o assunto, consulte Barreto (2005), Edler (1998, 1992) e Ferreira (1994, 1993). 
O autor discorre, também, sobre as diferentes lesões tissulares que poderiam contribuir para dificultar o diagnóstico do câncer uterino. Segundo ele, nenhum sinal característico era percebido no primeiro estágio da doença, e os evidentes eram comuns a outros tipos de afecções uterinas. Ozório ressalta que a microscopia e a anatomopatologia contribuíam para conferir maior precisão ao diagnóstico, mas isto só era possível através do exame das lesões tissulares extirpadas pelo cirurgião, geralmente, em uma etapa mais avançada da doença. O médico argumentava que, se fosse possível estudar as diversas fases da lesão, através do exame minucioso do tecido do órgão afetado, ainda haveria algumas dissonâncias sobre a natureza das alterações patológicas próprias do câncer "ou sobre os estados mórbidos que ele compreendia" (OZÓRIO, 1843, p. 5-6) . Concluía o estudo afirmando que, mesmo após uma intervenção cirúrgica, que resultara em aparente cura, a doença poderia voltar a se manifestar (OZÓRIO, 1843, p. 18). Esta recidiva da doença, mesmo após a extirpação da lesão, era denominada por vários autores de "diátese cancerígena" ou "predisposição ao câncer” (TÉALLIER, 1836, p. 37).

Apesar das dificuldades para estabelecer o diagnóstico precoce, naquela altura a medicina já havia dado um passo importante em relação aos estudos sobre o câncer. Data deste período o estudo realizado pelo patologista alemão Johannes Müller, que, em 1838, desenvolveu a teoria do blastoma, segunda a qual o câncer era constituído por células e não linfa. Anos mais tarde, Rudolf Virchow, discípulo de Müller, partiu da premissa de que se as células não nasciam da linfa, originando-se em células-mãe, o câncer também deveria se originar em uma célula normal, adquirindo, assim, categoria de tecido vivo, formado de novo - tecido neoplásico (COSTA, 2012, p. 69). Virchow, entretanto, imaginava que a doença era provocada por uma irritação crônica que se espalhava pelo organismo como uma espécie de líquido (FONSECA; TEIXEIRA, 2007, p. 15). Esta concepção foi modificada depois que o anatomista Wilhelm Waldeyer demonstrou, em meados do século XIX, que o processo de metástase resultava do transporte das células cancerosas pelo sistema linfático ou pela corrente sanguínea (FONSECA; TEIXEIRA, 2007, p. 15).

Entre as décadas de 1860 e 1890 a Gazeta Médica da Bahia repercutiu as propostas de novas terapias e os estudos experimentais sobre o câncer

6 A medicina, contudo, havia dado um passo importante em relação aos estudos sobre o câncer. Data deste período o estudo realizado pelo patologista alemão Johannes Müller, que, em 1838, desenvolveu a teoria do blastoma, segunda a qual o câncer era constituído por células e não linfa. Anos mais tarde, Rudolf Virchow, discípulo de Müller, partiu da premissa de que se as células não nasciam da linfa, originando-se em células-mãe, o câncer também deveria se originar em uma célula normal, adquirindo, assim, categoria de tecido vivo, formado de novo - tecido neoplásico (COSTA, 2012, p. 69). 
desenvolvidos no Brasil e no mundo. Muitos médicos buscaram tratamentos alternativos ao cirúrgico ou tentaram estabelecer, sem sucesso, a etiologia da doença. Na edição de janeiro de 1867, uma nota que avaliava uma pesquisa desenvolvida em Londres, pelo médico e professor de fisiologia W. H. Broadbent, concluía que, até aquela data, a natureza e a possibilidade de cura da doença ainda estavam envoltas em muitas controvérsias e a ciência tinha chegado a um dilema desconsolador: “- É cancro/ então é incurável. - Curou-se? Então não era cancro." Para o articulista, apesar dos avanços da medicina, a terapêutica do câncer não evoluíra, ficando "onde estava d'antes, na inefficacia da medicina, e na fallibilidade da cirurgia" (NOTICIARIO, 1867, p. 155).

Em 1892, uma circular dirigida à classe médica informava sobre a criação da "Liga Contra o Cancro" em Paris", na qual o comitê ratificava o pouco progresso da medicina nesse campo:

Curamos melhor os nossos operados, graças á antisepsia, mas não estamos mais adiantados sobre todos os outros pontos da história d'esta terrível affecção: etiologia, pathogenia, natureza intima, recidivas, etc. Em resumo, o cancro é uma vergonha para cirurgia contemporânea (CORRESPONDENCIA, 1892, p. 137).

O diagnóstico tardio era reputado como a principal causa da mortalidade por câncer na Bahia. Os médicos reconheciam que os primeiros sinais da doença não eram facilmente percebidos, nem pelos mais competentes profissionais. A ignorância da sociedade sobre a enfermidade, a aparente falta de sintomas e, certamente, o medo paralisante da morte, contribuíam para retardar a consulta ao médico. Assim, os doentes só recorriam ao médico quando o câncer já se encontrava em estágio avançado, não sendo mais possível sustar o seu desenvolvimento com os recursos médicos disponíveis.

As contribuições da física, da química e da biologia foram decisivas para a adoção de outros métodos terapêuticos a partir do final do século XIX. A descoberta dos raios X, na Alemanha, pelo físico Wilhelm Conrad Roentgen, em 1895, proporcionou a utilização da radiologia, inicialmente, no tratamento

7 A Liga Contra o Cancro tinha por objetivo estimular as pesquisas sobre a doença, oferecendo aos pesquisadores os meios para tal, e divulgar os resultados alcançados por meio de congressos e publicações em revistas especializadas. O comitê dirigente era composto pelos médicos Verneuil, Duplay, Trasbot, Straus, Metchnikoff, Reclus, Brault, Cazin, Rochard e Masson, pertencentes a instituições de renome como a Faculdade de Medicina de Paris, o Instituto Pasteur, "a Charité", a Academia de Medicina, dentre outras. Cf. Correspondencia (1892, p. 136-140). 
das displasias, depois nos cânceres cutâneos e, por fim, nos tumores internos (FONSECA; TEIXEIRA, 2007, p. 17).

Em 1903, a Gazeta Médica da Bahia publicou um artigo que discorria sobre os efeitos dos raios de Roentgen (raios X) nos diferentes tipos de sarcoma (COLEY, 1903, p. 181-182). Os Raios X e a radioterapia passaram a ser utilizados na terapêutica do câncer na Europa e Estados Unidos desde os primeiros anos do século XX. Apesar de essa tecnologia estar disponível na Bahia desde 1897, não há registros de utilização da radiologia para o tratamento do câncer na Bahia neste período(BRITTO, 1895, p. 395-406).

Muitos médicos viam com cautela a nova tecnologia, visto que a radiação, se utilizada em altas doses, contribuía para o desenvolvimento de câncer. Artigos publicados em edições posteriores continuavam a defender a intervenção cirúrgica precoce para ampliar a expectativa de vida das portadoras da doença. O recurso cirúrgico, entretanto, não se aplicava aos casos em que o câncer já se encontrava em estágio avançado (BESSON, 1904, p. 181-182; CANCRO..., 1908, p. 75; RESULTADOS..., 1908; LIMA, 1909).

Foi nesse cenário que o jovem médico e professor da Faculdade de Medicina da Bahia, Aristides Pereira Maltez, iniciou seus estudos de especialização em Ginecologia e Obstetrícia no New York Post-Graduate Medical School and Hospitale no Beth Israel Hospital de Nova Iorque no ano de 1909, onde principiou os estudos de Patologia Genital Feminina, destacando-se em cancerologia da mulher (LIGA BAHIANA CONTRA O CÂNCER, s/d, fl. 1). De volta à Bahia, passou a conciliar o trabalho na clínica particular com a docência na Faculdade de Medicina, após ser nomeado Assistente da Cadeira de Clínica Ginecológica em 1911, mesmo ano em que esta Cadeira foi instituída(COSTA, 2007, p. $118-120)^{9}$.

Em contato com pacientes afetadas pelo câncer, Maltez percebeu as dificuldades existentes para o tratamento da doença naquela conjuntura. Ciente da ignorância da sociedade a respeito dos sinais e sintomas da enfermidade, o que dificultava o acesso aos serviços médicos pelos acometidos, conhecedor também da fragilidade dos registros de morbi-mortalidade, Aristides Maltez suspeitava que o número de casos fosse muito superior ao de atendimentos realizados na sua clínica particular e no Hospital Santa Isabel.

8 Em 1897, o médico e professor da Faculdade de Medicina da Bahia, Alfredo Britto, trouxe um aparelho de radioscopia da Europa, instalado depois pelo médico no Hospital Santa Isabel, para auxiliá-lo no diagnóstico cirúrgico de afecções traumáticas (BRITTO, 1898, p. 395-406).

9 Em 1919, foi aprovado no concurso de Professor Substituto da 14. ${ }^{a}$ secção, Cadeira de Clínica Ginecológica, permanecendo nesta função até 1925, quando, mediante concurso, tornou-se Professor Catedrático de Ginecologia da Faculdade de Medicina da Bahia. Confira os documentos de nomeação disponíveis no acervo do HAM. 
O câncer era uma doença silenciosa, que não chamava a atenção dos poderes públicos, nem da sociedade e, portanto, não mobilizava nem os governantes, nem as autoridades sanitárias, nem a população. A doença só ganharia visibilidade no cenário nacional a partir da década de 1920, após a Reforma Carlos Chagas de 1919, que determinou a criação do Departamento Nacional de Saúde Pública (DNSP) e a consequente instituição da Inspetoria de Profilaxia da Lepra e das Doenças Venéreas, que estabeleceu a obrigatoriedade da notificação dos casos da doença (TEIXEIRA, 2010, p. 13-31; FONSECA; TEIXEIRA, 2007, p. 9-10).

A partir da determinação da obrigatoriedade das notificações dos casos da doença pelo DNSP, rompeu-se, progressivamente, a barreira do silêncio em torno da doença. A Bahia, entretanto, não dispunha de um centro de pesquisa e de uma estrutura capaz de oferecer serviços de diagnóstico e de tratamento da doença que atendesse à crescente demanda de enfermos em busca de tratamento médico. O Hospital Santa Izabel, pertencente à Santa Casa da Misericórdia, era o maior da Bahia, mas por seu caráter filantrópico, para lá convergiam os despossuídos, tanto da capital como do interior do estado. Faltavam leitos para acomodar tanta gente e recursos financeiros para ampliar as instalações do hospital. Esse quadro justificava, aos olhos de Aristides Maltez, a criação de um espaço específico para a pesquisa e tratamento gratuito do câncer - o Instituto de Câncer da Bahia. Contudo, o projeto do médico só se concretizaria algumas décadas depois, conforme veremos a seguir.

\section{A Liga Bahiana Contra o Câncer: educar para controlar a doença}

Enquanto o estudo do câncer no Rio de Janeiro, então Distrito Federal, estava relacionado à cadeira de Dermatologia e Sifilografia, na Bahia o câncer era, principalmente, do interesse da cadeira de Ginecologia. Portanto, a fundação da Sociedade de Ginecologia da Bahia, em 1932, foi um passo importante em direção ao controle da doença no estado.

Passados três anos, em sessão extraordinária da Sociedade de Ginecologia realizada nas dependências do Hospital Santa Isabel no dia 13 de dezembro de 1936, foi criada a Liga Bahiana Contra o Câncer - LBCC (FUNDADA..., 1936, p. 1). A LBCC tinha por finalidade promover a qualificação dos profissionais de saúde, difundir informações sobre a doença e angariar fundos pecuniários para construir o Instituto de Câncer da Bahia. 
Ruy de Lima Maltez, que presidia a Sociedade de Ginecologia à época e havia sido escolhido para chefiar a LBCC, acreditava que a Liga conferiria projeção aos trabalhos já realizados pela Sociedade de Ginecologia, contribuindo também para inserir os médicos baianos em um campo de estudos de amplitude internacional (MALTEZ, 1957, p. 7-8). Ao vincularem-se a campos de estudos emergentes no Brasil e no mundo, os médicos acumulariam capital simbólico, adquirindo notoriedade e autoridade através do monopólio da competência científica em um campo específico da medicina.

Uma série de eventos importantes precedeu a criação da liga da Bahia e pode ter servido de estímulo para os participantes daquela reunião. Em 1933, foi criada em Paris a L'Union Internationale Contre Le Cancer - UICC, idealizada por Jacques Bandaline com o objetivo de compartilhar, mundialmente, conhecimentos e competências entre médicos e pesquisadores da doença (ROWNTREE, 1934). No ano seguinte, 1934, foram criadas as ligas de São Paulo e a do Rio de Janeiro. A fundação das ligas de São Paulo, Rio de Janeiro e Bahia estavam em consonância com as propostas de combate à doença discutidas no I Congresso Brasileiro de Câncer realizado um ano antes, em 1935 (TEIXEIRA, 2010, p. 48).

A partir de julho de 1939, a LBCC iniciou uma série de campanhas educativas veiculadas nos meios de comunicação. Em 1940, Aristides Maltez foi ao rádio e aos jornais para divulgar informações diversas sobre o câncer, buscando conscientizar as pessoas sobre a necessidade do diagnóstico precoce e tratamento precoce e mobilizar a sociedade em torno do problema da assistência aos enfermos na Bahia (MALTEZ, 1957, p. 16-17). Panfletos e cartazes distribuídos pela Liga cuidavam sempre de enfatizar a necessidade do diagnóstico precoce e desestimular o tratamento com os chamados charlatães (SAMPAIO, 2006, p. 32).

Apesar dos esforços dos médicos, entre as décadas de 1930 e 1950, os números crescentes de adoecimentos e mortes por câncer continuavam a colocar em cheque a medicina e a assombrar os doentes, tal como ocorrera, por exemplo, com a tuberculose ao longo dos Oitocentos, sem, contudo, a aura romântica identificada com aquela doença. Restava a fé. Uns tinham fé que os avanços da ciência e da tecnologia biomédica conseguissem, se não extirpar de todo o mal, pelo menos o torná-lo inteligível e controlável. Alguns acreditavam que só forças sobrenaturais poderiam livrá-los daquele destino. Outros entendiam que para fazer frente a um mal daquela magnitude era necessário promover o consórcio de todas as forças, terrenas e espirituais, por isso recorriam ao auxílio concomitante de médicos, curandeiros, médiuns, sacerdotes e entidades espirituais de cultos diversos, cirurgias espirituais, dentre outros recursos.

Em que pesem as derrotas e vitórias da medicina e as motivações dos atores sociais, não se pode negar o esforço dos médicos para tornar visível uma doença silenciosa, ignorada pela sociedade e pelas autoridades políticas 
e sanitárias. Aristides Maltez era incansável, mantinha contato com Francisco Gentil, diretor da Faculdade de Medicina de Lisboa e presidente da Liga Contra o Câncer de Portugal, correspondendo-se também com o médico argentino Angel Honorio Roffo, diretor do Instituto de Medicina Experimental de Buenos Aires, na Argentina, a buscar apoio para o seu projeto (SAMPAIO, 2006, p. 35).

Roffo, que naquela altura era o maior especialista no estudo e tratamento do câncer da América Latina, remeteu a Maltez material necessário para a qualificação dos médicos baianos, além de receber João Andréa, professor da Faculdade de Medicina da Bahia, em curso de especialização promovido por ele. Conferências com especialistas locais, de outros estados e do exterior também concorriam para atualizar os médicos da Bahia sobre os estudos em desenvolvimento em outros centros e os mais recentes métodos profiláticos, de diagnóstico e terapêuticos.

No dia 2 de fevereiro de 1952, dezesseis anos depois da fundação da LBCC, a Liga pode, enfim, inaugurar o primeiro pavilhão do seu hospital, que passou a se chamar Hospital Aristides Maltez - HAM, em homenagem ao seu idealizador $^{10}$. A sua construção estaria sempre condicionada aos recursos financeiros liberados pelos órgãos governamentais e, por isso, foi realizada em várias etapas.

No quinquênio de 1952 a 1957, houve considerável esforço para qualificar profissionais na área de Oncologia, capacitar técnicos e aparelhar o novo hospital com as inovações tecnológicas necessárias. Estágios, cursos e bolsas de estudo foram concedidos nos mais avançados centros de combate à doença e vários especialistas foram convidados a vir à Bahia para discutir com os médicos locais diferentes aspectos da doença e da Cancerologia (SAMPAIO, 2006, p. 55).

Nesse período, seis mil quinhentos e oitenta e três pessoas foram atendidas no hospital, sendo detectados, dentre essas, mil casos de câncer. Muitos dos que recorreram ao hospital já estavam com a doença em estágio avançado (MALTEZ, 1957, p. 23). A ignorância e o medo a ela associado continuavam alimentando um círculo vicioso - o diagnóstico tardio diminuía as chances de cura, limitava os recursos da medicina, alimentava as estatísticas de morte, cuja divulgação contribuía para aumentar a crença na incurabilidade da doença e o medo paralisante da morte. Esse quadro começa a mudar lentamente com a instalação dos serviços de prevenção e diagnose da doença, como os ambulatórios preventivos, e os serviços de colposcopia e citologia.

Em paralelo às ações empreendidas pela Liga Bahiana Contra o Câncer, outras instituições buscavam aperfeiçoar os conhecimentos médicos na área da Oncologia. Em 1952, o Hospital das Clínicas da Faculdade de Medicina da Bahia promoveu o III Curso de Aperfeiçoamento de Ginecologia cujo foco era

10 Aristides Maltez morreu em janeiro de 1943, sem ter visto a concretização do seu projeto. 
o câncer ginecológico. Sob a orientação do professor catedrático de Ginecologia Alicio Peltier de Queiroz o curso tinha o objetivo de qualificar os médicos para a realização do diagnóstico precoce da doença (O PROBLEMA..., 1952, p. 5).

Alicio P. de Queiroz informou ao repórter que, apesar de importantes avanços obtidos no tratamento do câncer, os números de casos e óbitos devido à doença tinham crescido naqueles 30 anos. Para os médicos, a principal razão para a persistência de altas taxas de mortalidade era o diagnóstico tardio. Isto era bastante evidente no caso do câncer ginecológico, cuja ausência de sintomas no estágio inicial da doença demandava visitas ginecológicas regulares, para a realização de exames diagnósticos como a colposcopia e a citologia esfoliativa do colo do útero (O PROBLEMA..., 1952, p. 5).

Naquele período, a colposcopia era um exame que despendia tempo e recursos financeiros. O colposcópio, inventado na Alemanha em 1920 pelo ginecologista Hans Peter Hinselmann, era um aparelho caro e nem todos estavam familiarizados com o seu uso. A citologia esfoliativa do colo do útero, conhecida depois por Teste de Papanicolau, em homenagem ao médico patologista que desenvolveu o método, George Nicholas Papanicolaou, também era utilizada para detectar o carcinoma invasivo, antes que este se proliferasse (LÖWY, 2010, p. 55).

Os médicos baianos não desconheciam esses métodos. Todavia, Queiroz assinalava que, até aquela data, Salvador se encontrava desprovida dos equipamentos necessários à assistência aos doentes sem recursos pecuniários. Havia um Serviço Estadual de Câncer, com um chefe e três médicos assistentes, mas sem sede própria e sem o aparelhamento necessário para realizar o trabalho. $\mathrm{O}$ Hospital Santa Isabel e os demais hospitais de Salvador também não dispunham deste serviço. Por sua vez, o Hospital Aristides Maltez, que funcionava precariamente na sede da chácara Boa Sorte, ainda estava organizando um ambulatório para realizar o diagnóstico precoce do câncer ginecológico. Por conta da ausência deste procedimento, menos de $20 \%$ dos afetados pela doença chegavam aos hospitais "em condições de boa operabilidade" (O PROBLEMA..., 1952, p. 5).

$\mathrm{Na}$ maioria dos casos, a doença se instalava silenciosamente no corpo de mulheres aparentemente saudáveis sem que estas se dessem conta de seus efeitos devastadores. Fatores culturais concorriam para que os médicos não fossem os primeiros e únicos consultados. A transformação das mentalidades ocorre de forma muito lenta e persistia entre grande parte das mulheres baianas certo pudor em recorrer aos ginecologistas, majoritariamente homens. O medo paralisante da morte também contribuía para retardar a consulta ao médico. Assim, muitos doentes só buscavam o auxílio da medicina quando o câncer já se encontrava em estágio avançado, não sendo mais possível sustar o seu desenvolvimento com os recursos médicos disponíveis. 
Para Queiroz, as “propagandas berrantes" feitas no decorrer da Campanha Nacional do Câncer, em 1949, só serviram para alarmar a população, estimulando uma verdadeira "cancerofobia", especialmente entre os despossuídos, que por não terem acesso à assistência médica, acabariam por recorrer aos serviços dos charlatães. Queiroz afirmava também que de nada adiantava o aumento da "kilovoltagem dos aparelhos de Raios X", nem a indução à cirurgia aos inoperáveis. Isto só contribuiria para aumentar o exército de inválidos e mutilados. $\mathrm{Na}$ opinião do médico, “[...] a única assistência realmente profícua ao canceroso é montar ambulatórios para diagnosticar-lhe o mal nas primeiras fases da evolução, quando o tratamento dá $100 \%$ de resultados" (O PROBLEMA..., 1952, p. 5).

De acordo com o médico, os alunos da Faculdade de Medicina estavam sendo preparados para identificar os sinais da doença em seu início, impedindo, assim, que o mal se espalhasse de forma irrecuperável. O Hospital das Clínicas também matinha um Serviço Especial de Câncer anexo à Cátedra de Ginecologia, segundo Queiroz, perfeitamente aparelhado e articulado com o Departamento de Anatomia Patológica do hospital. Sob o encargo dos médicos Costa Filho e Geilza Batinga, ali eram realizados os exames de colposcopia e citologia vaginal, necessários à diagnose da doença. Para o médico, tais exames facultavam que o câncer fosse diagnosticado no estágio pré-clínico de evolução, em pessoas que não apresentavam nenhum sintoma da doença, o que contribuíra para aumentar o número de casos operáveis (O PROBLEMA..., 1952, p. 5).

Apesar do otimismo de Alicio Peltier de Queiroz a respeito da utilização das técnicas de diagnóstico precoce e de tratamento cirúrgico do câncer, esta posição não era unânime. Os ginecologistas reconheciam que a citologia vaginal contribuiu para estabelecer o diagnóstico de neoplasias malignas anteriormente insuspeitas, mas, muitas vezes, as mulheres submetidas ao método foram diagnosticadas com alterações proliferativas menos pronunciadas, denominadas de displasias (LÖWY, 2010, p. 55). Essas alterações evoluíam muito lentamente e nem todas as lesões evoluíam para um câncer. Muitos médicos optavam, então, por acompanhar a evolução das lesões sem utilizar terapias invasivas como a radioterapia e a histerectomia, especialmente, em mulheres jovens e em idade fértil.

O dilema era que os médicos não tinham certeza sobre a natureza de tais lesões, nem conseguiam correlacionar a morfologia da lesão com seu estado final. Na dúvida, a maioria optava por extirpar o útero logo no estágio inicial da lesão, para evitar o câncer. Era algo como "corta-se o dedo para não perder a mão". Segundo Löwy (2010, p. 56), contudo, esta opção se baseava em dados clínicos sólidos. No início da década de 1950, praticamente todas as mulheres diagnosticadas no estágio inicial do câncer do colo do útero, tratadas por histerectomia, ficaram livres da doença. Desta forma, o tratamento continuava sendo, 
preferencialmente, cirúrgico e o sucesso do método não era $100 \%$ garantido como propalava Alicio Peltier de Queiroz.

Lidar com o câncer, portanto, não era tarefa fácil nem para os pacientes, nem para os médicos. Quando não havia recidiva, a cirurgia em si podia se constituir em risco, deixar sequelas indesejáveis. O câncer e as intervenções para conter o mal alteravam as expectativas e a trajetória de vida do acometido pela doença em vários níveis: individual, familiar e social. Talvez por isso, muitos se faziam de surdos aos seus sinais, só recorrendo à medicina quando se tornava impossível ignorá-los. A fama de incurabilidade da doença também afastava muitos acometidos dos recursos médicos. Para que se submeter à tortura daqueles procedimentos se o fim era certo?

\section{Considerações finais}

Até o início do século XX, o câncer era uma doença silenciosa, que não demandava grande atenção dos médicos, das autoridades, nem da sociedade. As teses publicadas pela Faculdade de Medicina da Bahia (FMB) e artigos veiculados na Gazeta Médica da Bahia, versando sobre o câncer, comprovam que esta doença já era conhecida pelos médicos baianos desde a década de 1840 . Todavia, o conhecimento sobre a doença era incipiente e não havia nenhuma ação institucionalizada voltada para o controle da doença. Só a partir da década de 1920, ações mais efetivas de médicos, filantropos e até mesmo do Estado começaram a tomar corpo acompanhando as transformações da tecnologia médica, da biomedicina e do cenário político-administrativo brasileiro.

O posicionamento dos poderes instituídos, dos médicos e da sociedade em geral em relação ao câncer estava conexo com as transformações ocorridas no período estudado. No final da década de 1910, inicia-se progressiva intervenção dos poderes públicos no âmbito da saúde e a instituição da obrigatoriedade da notificação da doença conferiu maior visibilidade ao câncer. A ampliação da expectativa de vida verificada na Europa a partir da segunda metade do século XIX contribuiu para o aumento de casos de câncer e número de mortes, o que implicou na criação de instituições voltadas para pesquisa e tratamento da doença. Informados do que estava sendo produzido nos centros científicos e acadêmicos da América do Norte e do Velho Mundo, os médicos baianos associaram-se para empreender ações voltadas para o controle do câncer na Bahia e ingressar em um campo de estudos de amplitude internacional. 
Considera-se que o esforço para qualificar os profissionais da saúde para lidar com a doença e os doentes, através de cursos de especialização e conferências promovidos pela Liga Bahiana Contra o Câncer e pela Faculdade de Medicina da Bahia, foi uma ação importante no processo de educação para o controle do câncer na Bahia.

Em âmbito mais largo ou mais restrito, circulando tanto entre a classe médica quanto entre os pacientes, suas famílias e a população letrada, os periódicos médicos ou leigos exerceram também uma função educativa, na medida em que contribuíam para divulgar informações sobre uma doença silenciosa e silenciada por muito tempo na Bahia. Avalia-se que as publicações sobre o câncer, tanto nos meios de comunicação de massa quanto nos periódicos especializados, se constituíram em ações educativas que contribuíram para dar visibilidade à doença, mobilizar a sociedade e desencadear políticas públicas e ações filantrópicas.

\section{REFERÊNCIAS}

BARRETO, J. B. A Organização da saúde pública no Brasil. Arquivo de Higiene, Rio de Janeiro, v. 12, n. 2, p. 169-215, 1942.

BARRETO, M. R. N. A medicina luso-brasileira. Instituições, médicos e populações enfermas em Salvador e Lisboa (1808-1851). Tese (Doutorado em História das Ciências da Saúde) - Casa de Oswaldo Cruz - Fiocruz, Rio de Janeiro, 2005.

BESSON. Tratamento cirúrgico do cancro do útero. Gazeta Medica da Bahia, Salvador, n. 36, p. 182-183, 1904.

BRITTO, A. Contribuição para o estudo da 'gripe-influenza' em 1895. Gazeta Medica da Bahia, Salvador, n. 27, p. 234-237; 257-272, 1895.

CANCRO do útero inoperável. Gazeta Médica da Bahia, Salvador, n. 40, p. 75, 1908.

COLEY. Influência dos raios de Roentgen sobre as diferentes formas de sarcoma. Gazeta Médica da Bahia, Salvador, n. 35, p. 181-182, 1903.

CORRESPONDENCIA. Liga contra o cancro. Circular á classe medica. Gazeta Médica da Bahia, Salvador, n. 24, p. 136-140, 1892.

COSTA, J. de S. Histórico da Ginecologia na Faculdade de Medicina da Bahia. Gazeta Médica da Bahia, Salvador, v. 77, n. 2, p. 117-124, jul./dez. 2007.

COSTA, R. M. P. Luta Contra o Cancro e Oncologia em Portugal. Estruturação e normalização de uma área científica (1839-1974). Porto: CITCEM; Afrontamento, 2012. 
EDLER, F. C. A medicina brasileira no século XIX: um balanço historiográfico. Ásclepio, Madrid, v. L, n. 2, p. 169-186, 1998. Disponível em: <http://asclepio.revistas.csic.es>. Acesso em: 7/6/2014.

. As Reformas do Ensino Médico e a Profissionalização da Medicina na Corte do Rio de Janeiro 1854-1884. Dissertação (Mestrado em História Social) - Departamento de História, FFLCH, Universidade de São Paulo, São Paulo, 1992.

FERREIRA, L. O. Das doutrinas à experimentação: rumos e metamorfoses da medicina no século XIX. Revista da SBHC, Rio de Janeiro, n. 10, p. 43-52, 1993.

. João Vicente Torres Homem: descrição da carreira médica no século XIX. Physis, Rio de Janeiro, v. 4, n. 1, p. 57-77, 1994.

FONSECA, C. O.; TEIXEIRA, L. A. De doença desconhecida a problema de saúde pública: o INCA e o controle do câncer no Brasil. Rio de Janeiro: Ministério da Saúde, 2007.

FUNDADA uma sociedade para combater o câncer. Importante reunião médica no H. Santa Izabel. A Tarde, Salvador, p. 1, 15 dez. 1936.

GUIMARÃES, C. Bahia e mais um hospital. A Tarde, Salvador, p. 3, 19 jul. 1932.

LIGA BAHIANA CONTRA O CÂNCER. Resumo biográfico do Prof. ${ }^{\circ}$ Aristides Maltez. Salvador: Hospital Aristides Maltez, Biblioteca Mario Kroeff, s.d. Mimeo.

LIMA, A. R. Tratamento dos carcinomas do útero. Gazeta Médica da Bahia, n. 41, p. 199-210; 267-276, 1909.

LIMA, P. A cura do câncer pelo radium. Gazeta Médica da Bahia, Salvador, n. 57, p. 571-574, 1927.

. Sobre a cura do câncer pelo radium. Gazeta Médica da Bahia, Salvador, n. 58, p. 15-24, 1927.

. Sobre alguns casos da língua curados pelo radium. Gazeta Médica da Bahia, Salvador, n. 58, p. 547-54, 1928.

LÖWY, I. Cancer, women, and public health: the history of screening for cervical cancer. História, Ciências, Saúde - Manguinhos, Rio de Janeiro, v. 17, supl. 1, p. 53-67, 6 jul. 2010.

MALTEZ, R. de L. Esboço Histórico da Campanha Contra o Câncer na Bahia. Arquivos de Oncologia, Salvador, p. 8-25, 1957.

MEIRELLES, N. S. et al. Teses Doutorais de Titulados pela Faculdade de Medicina da Bahia, de 1840 a 1928. Gazeta Médica da Bahia, Salvador, v. 74, n. 1, p. 9-101, jan./ jun. 2004.

NOTICIARIO. Novo tratamento para o cancro. Gazeta Médica da Bahia, Salvador, n. 1, p. $155,1867$.

O PROBLEMA do cancer na Bahia. Diario da Bahia, Salvador, p. 5, 18 nov. 1952. 
OZÓRIO, A. J. Signaes pelos quaes se póde reconhecer o cancro do utero e o diagnostico differencial entre as ulcerações e o cancro do mesmo órgão. These apresentada, $\mathrm{e}$ sustentada, no dia 16 de novembro de 1843 perante o jury da Faculdade de Medicina da Bahia no concurso para o logar de substituto da secção cirúrgica. Salvador: Typ. de Epifanio, 1843.

RESULTADOS longínquos do tratamento do cancro do uterino pela histerectomia abdominal. Gazeta Médica da Bahia, Salvador, n. 39, p. 560; n. 40, p. 71-74, 1908.

REVISTA da Imprensa Médica. O micróbio do cancro. Gazeta Médica da Bahia, n. 19, p. $507-13,1888$.

ROSENBERG, C. E. Explaining epidemics and other studies in the history of medicine. New Brunswick (N.J): Rutgers University Press, 1992.

ROWNTREE, C. L'Union Internationale Contre Le Câncer. The British Medical Journal, London, v. 2, n. 3850, p. 742, Oct. 20, 1934. Disponível em: <http://www.uicc.org/index. php?option=com_content\&task=view\&id=15975\&Itemid=339>. Acesso em: 12/6/2010.

SAMPAIO, C. N. 70 Anos de Lutas e Conquistas: Liga Bahiana Contra o Câncer. Salvador: LBCC, 2006.

TÉALLIER, P. J. S. Traité Du Cancer de La Matrice, de ses causes, de son diagnostic et de son traitement: Des pertes séminales involontaires; par M. Lallemand. Bruxelles: H. Dumont, 1836.

TEIXEIRA, L. A. O controle do câncer no Brasil na primeira metade do século XX. História, Ciências, Saúde-Manguinhos, Rio de Janeiro, v. 17, supl. 1, p. 13-31, jul. 2010.

Texto recebido em 15 de outubro de 2014. Texto aprovado em 21 de outubro de 2014. 